\title{
Survey of Canine Heartworm in the City of Recife, Pernambuco, Brazil
}

\section{Leucio Câmara Alves $/^{+}$, Leila Vânia de Almeida Silva, Maria Aparecida da Gloria Faustino, John Wilson McCall*, Prasit Supakonderj*, Norma Wolmer Labarthe**, Milton Sanchez $^{* * *}$, Ortiz Caires}

\author{
Departamento de Medicina Veterinária, Universidade Federal Rural de Pernambuco, Av. Dom Manoel de \\ Medeiros s/nº, 52171-900 Recife PE, Brasil *Department of Parasitology, University of Georgia, Athens, 30605 \\ GA, USA **Faculdade de Veterinária, Centro de Ciências Médicas, Universidade Federal Fluminense, \\ 6424230-340 Niterói, RJ, Brasil ***Novartis Biociência SA, 04706-900 São Paulo, SP, Brasil
}

Six hundred and eleven random-source dogs (338 male, 273 female) one year of age or older, from six sections of the city of Recife, Pernambuco, were examined antemortem for circulating microfilariae Dirofilaria immitis and Dipetalonema reconditum adult heartworm (D. immitis) antigen, and examined postmortem for adult heartworms. The prevalence of heartworm infection was $2.3 \%$ (14/611), as determined by necropsy for adult worms, and 1\% (6/611) had circulating microfilariae of D. immitis; thus, $57.1 \%$ of the heartworm-infected dogs had occult infections. The results of serological testing indicated that $1.3 \%$ (8/611) of the dogs were positive for adult heartworm antigen. A total of $42(6.9 \%)$ of the dogs had microfilariae of D. reconditum; 40 of these had only D. reconditum and two additional dogs had microfilariae of both species, D. immitis and D. reconditum.

Key words: dirofilariasis - Dirofilaria immitis - heartworm - Recife - Brazil

Dirofilariasis, due to infection with Dirofilaria immitis, is an important disease of small animals, causing severe cardiopulmonary problems and even death of some animals. Its prevalence may be quite high in some animals, particularly among domestic dogs (the natural host), coyotes, domestic cats, and ferrets, but it has been reported in over 30 species of animals and there have been numerous reports of infection in humans (Otto 1975). Of at least ten species of filariids known to infect domestic dogs, only $D$. immitis is known to produce serious pathogenic changes in this host.

The heartworm parasite is transmitted by mosquitoes. Although more than 70 species of mosquitoes have been shown support development of the microfilariae to the infective third stage in the laboratory, it is generally accepted that only a few species of mosquitoes are responsible for transmitting the parasite to susceptible animals under natural conditions (Otto \& Jackowski 1981). The transmission pattern varies substantially from region to region. In some places, $50 \%$ of the dogs are infected, while

\footnotetext{
${ }^{+}$Corresponding author. Fax: +55-81-441.1711. E-mail: alves@elogica.com.br

Received 12 November 1998

Accepted 22 April 1999
}

in other geographical regions no animals are infected (Luzon-Pena \& Gomez-Bautista 1993).

Historically, diagnosis of canine heartworm disease has been based on finding microfilariae of D. immitis in the blood. Methods of detecting microfilaria include direct blood smears, the modified Knott test, filter techniques, and specific histochemical methods (e.g., acid phosphatase activity). During the past decade, a variety of immunodiagnostic tests have been investigated. Since counter immunoelectrophoresis was used successfully in detecting $D$. immitis antigen in sera from infected dogs (Weil et al. 1985), several adult heartworm antigen tests, most of them Elisa-based, have been developed and are now available commercially (McTier et al. 1995).

In the city of Recife, State of Pernambuco, the first attempts to map canine filarioses were made by Pimentel and Alves (1987), Pimentel et al. (1988), and Alves et al. (1993), all of them surveyed some areas of the city by examining dogs for microfilariae. However, they did not identify the species of microfilariae involved. Thus, the real prevalence of heartworm infection in this area has remained unknown. The study reported herein provides a prevalence of heartworm infection in dogs in Recife, by necropsy for recovery of adult worms, as well as by examination for microfilariae and adult antigens. The prevalence of $D$. reconditum, as determined by the presence of circulating microfilariae, is also presented. 


\section{MATERIALS AND METHODS}

Area of survey - Recife $\left(209 \mathrm{~km}^{2}\right)$, the capital of the State of Pernambuco, is located in the northeast of Brazil. The city is divided into six sections, denoted "Regiões Administrativas" RPA 1 through 6 , according to their geographical location (Figure).

Blood samples and necropsy - Studies were performed on a total of 611 pound dogs one year of age or older from various sites in Recife, from August 1996 to February 1998. Whole blood in EDTA and plasma samples were collected from all animals before euthanasia. All dogs were euthanized by intravenous administration of a barbiturate and heparin and then necropsied.

Microfilarial examination - The whole blood was examined for the presence of microfilariae of $D$. immitis or D. reconditum by the modified Knott test (Knott 1939). The species of microfilariae were distinguished as described by Redington et al. (1978).
Antigen testing - The sera were tested for adult D. immitis antigens, immediately after collection of blood. An Elisa test (DiroCHEK ${ }^{\circledR}$, Synbiotics Corporation, San Diego, CA) was run on all samples. Plasma samples were categorized as follows: (a) amicrofilaremic with adult heartworm(s) at necropsy (G1); (b) microfilaremic with adult heartworm(s) (G2); and (c) noninfected (G3).

The discrepant samples were tested by the Snap test (IDEXX Laboratories, Portland, Maine).

\section{RESULTS}

Table I shows the number of male and female dogs tested and those found microfilaremic. Three different groups of microfilaria-positive dogs were found in Recife (Table II). The first group had single infection of $D$. reconditum $(6.6 \%)$, the second had single infection of D. immitis $(0.7 \%)$, and the third had mixed infections of both species $(0.3 \%)$.

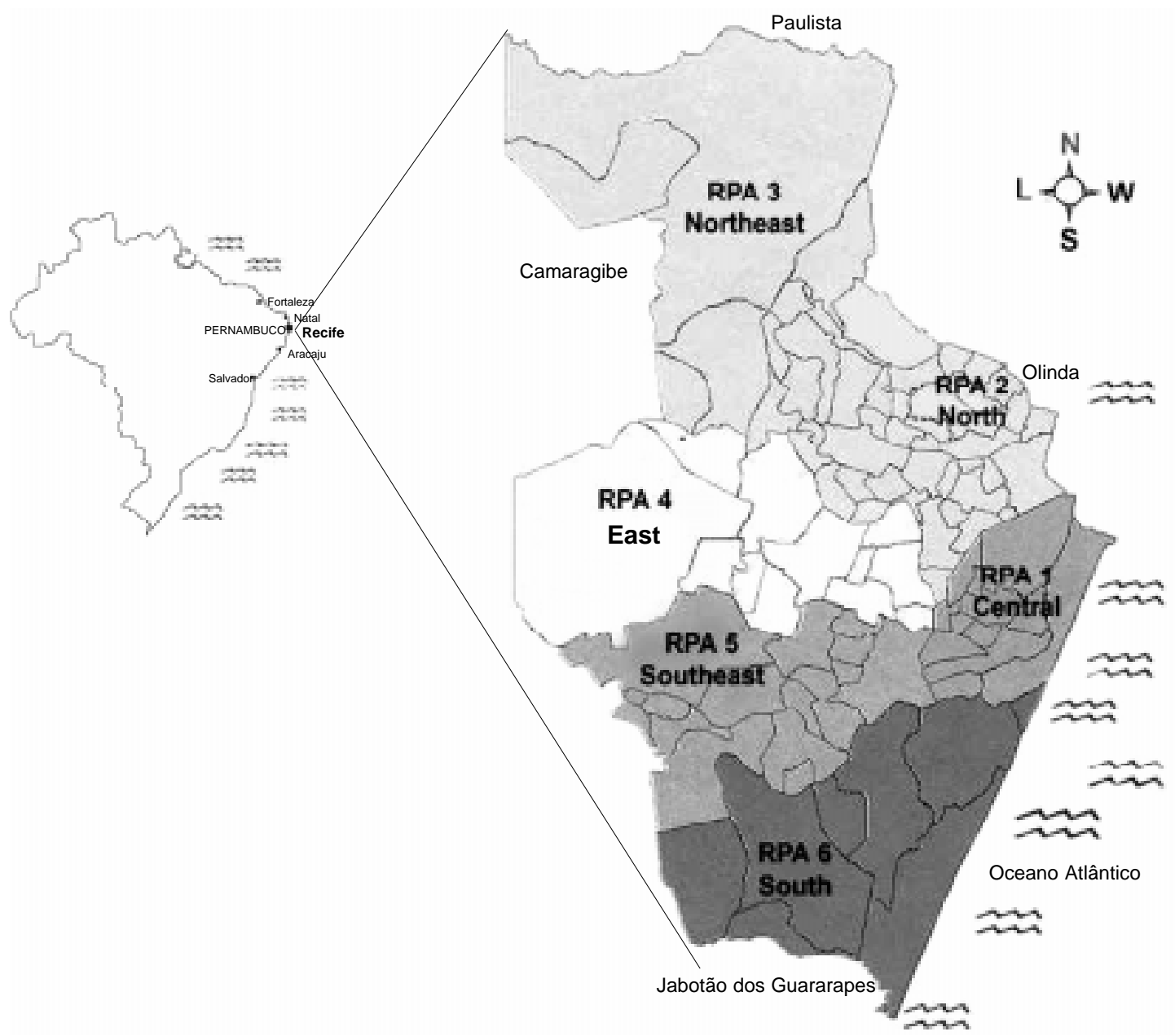

Surveyed areas of the city of Recife with sections estabilished according to the City Hall. 


\section{TABLE I}

Prevalence of microfilariae, by sex, according to the detection of microfilariae ( $\mathrm{mf}$ ) by the modified Knott test, among dogs in Recife, Brazil

\begin{tabular}{lccc}
\hline $\begin{array}{l}\text { Knott } \\
\text { test }(\mathrm{mf})\end{array}$ & Male dogs & Female dogs & Total samples \\
\hline $\begin{array}{l}\text { Positive } \\
\text { Negative }\end{array}$ & $031(5.1 \%)$ & $015(2.45 \%)$ & $046(7.5 \%)$ \\
\hline Total & $338(55.3 \%)$ & $253(42.2 \%)$ & $565(92.5 \%)$ \\
\hline
\end{tabular}

\section{TABLE II}

Detection of species of microfilariae $(\mathrm{mf})$ by the modified Knott test, according to the sex of infected dogs in Recife, Brazil

\begin{tabular}{lccc}
\hline Knott test (mf) & $\begin{array}{c}\text { Male } \\
\text { dogs }\end{array}$ & $\begin{array}{c}\text { Female } \\
\text { dogs }\end{array}$ & $\begin{array}{c}\text { Total } \\
\text { samples }\end{array}$ \\
\hline $\begin{array}{l}\text { Dipetalonema } \\
\text { reconditum }\end{array}$ & $27(4.4 \%)$ & $13(2.1 \%)$ & $40(6.6 \%)$ \\
$\begin{array}{l}\text { Dirofilaria } \\
\text { immitis }\end{array}$ & $2(0.3 \%)$ & $2(0.3 \%)$ & $4(0.7 \%)$ \\
Mixed infection & $2(0.3 \%)$ & 0 & $2(0.3 \%)$ \\
\hline
\end{tabular}

Thus, by microfilarial testing alone, the prevalence of infection for $D$. immitis and $D$. reconditum was $1 \%$ and $6.9 \%$, respectively. Microfilariae were detected more frequently in males than in females in all groups of dogs, and mixed infection was found only in male dogs. Eight (57.1\%) of the 14 dogs with worms in the heart and lungs at necropsy were amicrofilaremic (i.e. had occult infections or G1). Six dogs were microfilaremic with adult heartworm (G2). Five hundred and ninety seven were noninfected animals (G3).

The postmortem examination indicated that 14 of the 611 dogs had adult heartworms. Thus, the actual prevalence of heartworm infection was $2.3 \%$. Antigen was detected in $8(57.1 \%)$ of these 14 dogs.

The section with the highest prevalence of dirofilariasis was RPA5 (35.71\%), followed by RPA 4 (21.4\%) and RPA 3 and RPA 2 (14.3\%). The highest prevalence of dipetalonematosis was found in RPA 2 (33.3\%), followed by RPA 5 $(28.6 \%)$ and RPA 3 (23.8\%).

\section{DISCUSSION}

The first attempt in areas close to Recife, to map canine filarioses was made by Pimentel and Alves (1987), who found $28.7 \%$ of the dogs tested with microfilaremia in Itamaracá Island. Pimentel et al. (1988) later reported that $2 \%$ of the dogs in Caruaru were positive for microfilariae, and Alves et al. (1993) reported microfilariae using the Knott test in $11.6 \%$ of the dogs in Dois Irmãos community. However, none of these identified the species of filariae involved. This is the first research in which the species of filariids involved was determined. D. reconditum was more frequently encountered than $D$. immitis.

Heartworm was expected to be more prevalent in Recife, because of the abundance of mosquitoes. Medeiros et al. (1992) studied the rate of infectivity for Wuchereria bancrofti in mosquitoes in Recife and found it to be $0.61 \%$ in Culex quinquefasciatus. Due to the low percentage of infected dogs and the low microfilaremias, it is probable that the rate of infectivity for $D$. immitis in mosquitoes is lower than that observed for $W$. bancrofti. In this study, we found only $2.3 \%$ of animals with adult heartworms. The rate of infection in mosquitoes generally correlates with the number of microfilariae in patients, whether humans or animals. In this study, the microfilaremia in dogs infected with $D$. immitis was low or absent. Studies of the mosquito populations should be conducted to evaluate the biology of this infection. In the present study, the occult dirofilariasis rate was higher $(57.1 \%)$. Labarthe et al. (1997) suggested that the abusive use of microfilaricidal agents contributed substantially to the elevated rate of occult dirofilariasis.

Heartworm antigen was detected in only $57.1 \%$ of the dogs harboring adult heartworms at necropsy. The positive and negative predictive values for these adult heartworm antigen test kits varies with prevalence of infection (Grieve \& Thomas 1986). The percentages of false-negative and false-positive results, particularly the former, are considerably higher in areas of low prevalence than in areas of high prevalence. Furthermore, these tests detect only female worms and are not consistently positive unless more than one female worm eight months of age or older are present (McCall 1994). Thus, the low percentage of false-negative antigen test results in the present survey is as expected.

In the present survey, D. immitis infection was encountered less frequently than $D$. reconditum infection. The results show the highest prevalence of $D$. immitis in section RPA 5, followed by RPA 4 and RPA 3 and RPA 2. These impoverished areas are forested and probably serve as ideal habitats for the development of mosquitoes. On the other hand, the highest percentage of dogs infected with D. reconditum was recorded for section RPA 2, followed by RPA 5 and RPA 3. The location, low socio-economic conditions, and urbanization of these areas contribute to the high density of fleas, and thus the presence of this filarial infection, in these sections of the city. 


\section{REFERENCES}

Alves LC, Cole EF, Athayde ACR 1993. Prevalência da filariose canina no Bairro de Dois Irmãos. Rev Bras Parasitol Vet 2 (Suppl.1): 68.

Grieve RB, Thomas CB 1986. Evaluation of commercially-available assays for serodiagnosis of canine Dirofilaria immitis infection, p. 87-90. In GF Otto, Proceedings of the Heartworm Symposium '86, American Heartworm Society, Washington, DC.

Knott J 1939. A method for making microfilarial surveys on day blood. Trans R Soc Trop Med Hyg 33: 191-196.

Labarthe NW, Almonsky N, Guerreiro J, Duque-Araújo A 1997. Description of the occurrence of canine dirofilariasis in the State of Rio de Janeiro, Brazil. Mem Inst Oswaldo Cruz 92: 47-51.

Luzon-Pena M, Gomez-Bautista M 1993. Epidemiologia da dirofilariose. Canis et Felis 3: 19-31.

McCall JW 1994. Participation by academia in discovery and development of products by the animal health industry, p. 143-151. Proceedings, Veterinary Pharmacology in the Pharmaceutical Industry: Ninth Biennial Symposium of the Academy of Veterinary Pharmacology and Therapeutics, Kalamazoo, Michigan.

McTier TL, McCall JW, Supakornderj N 1995. Features of adult heartworm test kits, p. 115-126. In MD Soll. \& DH Knight (eds), Proceedings of the Heartworm Symposium '95, American Heartworm Society, Batavia, IL.
Medeiros Z, Dreyer G, Andrade LD, Pires ML, Mendes J, Pimentel R 1992. Wuchereria bancrofti microfilarial density of autochthonous cases and natural Culex infectivity rates in Northeast Brazil. J Trop Med Hyg 95: 214-217.

Otto GF 1975. Occurrence of the heartworm in unusual locations and in unusual hosts, p. 6-13. In GF Otto, Proceedings of the Heartworm Symposium '74, KS, VM Publishing Co., Bonner Springs.

Otto GF, Jackowski LA 1981. Mosquitoes and canine heartworm disease, p. 17-32. In GF Otto, Proceedings of the Heartworm Symposium '80, KS, VM Publishing Co., Edwardsville.

Pimentel A, Alves LC 1987. Estudos epidemiológicos preliminares na população canina de Itamaracá-PE. In I Simpósio Nacional de Filariose, Abstract, Recife, PE.

Pimentel A, Bezerra MJG, Pontual SA, Oliveira DSC, Soares PC, Leite A, Bezerra R, Alves LC 1988. Prevalência da filariose canina no município de Caruaru, PE. Abstract, 32. In XXI Congresso Brasileiro de Medicina Veterinária, Salvador, BA.

Reddington BC, Ronald FJ, Goodwin SW, Otto GF 1978. The various microfilariae found in dogs in the United States, p. 14-21. In GF Otto, Proceedings of the Heartworm Symposium '77, KS, VM Publishing Co., Bonner Springs.

Weil GJ, Malane MS, Powers PG, Blair LS 1985. Monoclonal antibodies to parasite antigens found in the serum of Dirofilaria immitis-infected dogs. J Immunol 134: 1185-1191. 